\title{
Perioperative pentoxifylline therapy attenuates early postoperative neuro-cognitive decline in patients undergoing coronary artery bypass grafting surgery using cardiopulmonary bypass
}

\author{
Sambhunath Das, Suparna Kailash ${ }^{1}$, Manu Mehta ${ }^{1}$, Akshya Kumar Bisoi ${ }^{2}$
}

\begin{abstract}
Background: Postoperative cognitive decline (POCD) after coronary artery bypass grafting (CABG) is a common problem. Studies show that pentoxifylline administration reduces inflammation induced by cardiopulmonary bypass and brain injury after ischaemia. Hence the perioperative use of pentoxifylline in attenuating POCD was evaluated in the study. Materials and Methods: Eighty patients were divided randomly into two groups from 106 patients scheduled for CABG surgery. The study group was administered pentoxifylline $400 \mathrm{mg}$ twice daily orally from day of admission to 7th day after surgery, whereas the control group patients received placebo. Neurocognitive assessment was assessed by an independent clinical psychologist one day after admission to hospital and again on 7th postoperative day. The data was analyzed and a $P<0.05$ was considered significant results. Results: Pentoxifylline-treated group showed no statistically significant difference in animal naming test scores ( $10.3 \pm 2.2$ versus $9.4 \pm 2.5, P=0.07)$, digit symbol substitution test $(26.1 \pm 7.47$ vs $22.2 \pm 6.07, P=0.09)$ and 8 subtests of Post Graduate Institute-memory scale. The control group had significant $P O C D$ as detected by animal naming test $(10.5 \pm 3.7$ versus $8.6 \pm 3.9, P=0.008)$, digit symbol substitution test $(20.2 \pm 8.2$ versus $14.7 \pm 8.9, P=0.008)$ and five subtests of memory scale $(P=0.01,0.04$, $0.003,0.005$ and 0.02 ). The incidence of POCD was $50 \%$ in placebo-treated group compared to $22.5 \%$ in pentoxifylline group. Conclusions: The perioperative use of pentoxifylline attenuates the early postoperative neurocognitive decline after CABG using cardiopulmonary bypass.
\end{abstract}

Key words: Cardiopulmonary bypass, coronary artery bypass grafting, neurocognitive assessment tests, pentoxifylline, postoperative neurocognitive decline

\section{INTRODUCTION}

The number of patients undergoing coronary artery bypass grafting $(\mathrm{CABG})$ for the management of coronary

\begin{tabular}{|l|l|}
\hline \multicolumn{2}{|c|}{ Access this article online } \\
\hline Quick Response Code: & Website: \\
\hline & www.jnaccjournal.org \\
\cline { 2 - 3 } & \\
\hline
\end{tabular}

artery disease is increasing every year. Postoperative neurocognitive decline (POCD) and stroke are associated with CABG using cardiopulmonary bypass (CPB). ${ }^{[1,2]}$ Zamvar et al estimated that around $63 \%$ of patients undergoing CABG on $\mathrm{CPB}$ and $27 \%$ of patients undergoing $\mathrm{CABG}$ off pumpshow signs of cognitive decline at the time of discharge. ${ }^{[3]}$ Cerebral injury after CABG increases the length of hospital stay, cost of medical expenditure, morbidity and mortality of the patients. ${ }^{[1,4]}$

Various attempts in attenuating the POCD have been tried by improvements in biomaterials, pharmacological,

Departments of Cardiac Anaesthesia, ${ }^{1}$ Psychiatry, ${ }^{2}$ Cardiothoracic and Vascular Surgery, All India Institute of Medical Sciences, New Delhi, India

Dr. Sambhunath Das, Department of Cardiac Anaesthesia, 7th Floor, Cardio thoracic sciences Centre, All India Institute of Medical Sciences, Ansari Nagar, New Delhi-110 029, India. E-mail: sambhunathds833@gmail.com 
anaesthetic and surgical managements. ${ }^{[5]}$ The complete attenuation of POCD is not achieved so far. Therefore some new effective intervention is necessary to overcome POCD. Recently few studies show that pentoxifylline (PTX) administration reduces inflammation generated from CPB. ${ }^{[6]}$ Pentoxifylline with blood viscosity lowering and immunomodulatory property improves microcirculation and oxygenation of brain. ${ }^{[7]}$ Few animal studies have shown that PTX protects brain by reducing inflammation and hypoxic - ischaemic injury. ${ }^{[8,9]}$

To the authors' best knowledge, there are no studies on PTX in preserving POCD after CABG with CPB in the English language. We hypothesised that perioperative therapy of PTX will attenuate the POCD in patients undergoing CABG. Hence the objectives of the study were to assess the impact of perioperative PTX therapy on POCD, by using neurocognitive assessment (NCA) tests in patients undergoing $\mathrm{CABG}$ surgery with $\mathrm{CPB}$.

\section{MATERIALS AND METHODS}

\section{Study Design}

The prospective randomised clinical trial was conducted between October 2009 to September 2012 in the Cardiothoracic Centre of All India Institute of Medical Sciences; a tertiary care hospital at New Delhi in India. It received ethical approval from the institutional ethics committee. Written informed consent was obtained from all patients to participate in the study and they were free to withdraw at any time.

\section{Patient selection}

One-hundred and six patients age between 40 and 65 years scheduled for elective on pump CABG were considered for the study. Patients with neurological, psychiatric, carotid artery disease, renal disease, liver disease, emergency surgery, recent myocardial infarction, repeat surgery, coagulation disorder, use of anti-inflammatory drug like steroid, patients with a history of allergy to PTX and uncontrolled diabetes mellitus were excluded from the study. Twentysix patients were excluded for various reasons, 80 patients were allocated into two groups by using a computer-generated randomised list according CONSORT guidelines [Figure 1]. Groups PTX $(n=40)$ received PTX $400 \mathrm{mg}$ twice daily orally from the day of admission to 7 th day after surgery. The control group was administered matching placebo prepared by a pharmaceutical company (Group placebo). The PTX and placebo tablet was given to the patients and checked by nurses who were unaware to the study.

\section{Statistical analysis and sample size calculation}

There is lack of published study on effect of PTX on POCD in cardiac surgical patient. The incidence of POCD after CABG using CPB is $63 \%$ in a study by Zamvar et al..$^{[3]}$ We assumed $50 \%$ reduction of POCD after PTX treatment and the probable incidence would be $31.5 \%$. Taking a of 0.05 and $80 \%$ power, for a two-tailed study the estimated minimum sample size for each group would be 38 . In order to achieve better power of study we increased the sample size to 40 in each group.

Data analysis was performed using SPSS 15.0 (Chicago, IL) software package. Data were recorded and tabulated with excel software (Microsoft Corp, Redmond, WA). Data are presented as mean and standard deviation (SD), percentage and frequency unless otherwise indicated. Demographic details, illness variables, anaesthesia and surgical details were recorded using a semi-structured pro-forma. All the quantitative baseline variables were compared using paired t-test or unpairedt-test between the two groups, whereas all the categorised variables was compared using $\chi^{2}$ or Fisher's exact test while change within groups was seen by paired test or Wilcoxon Signed ranks or McNemar test as applicable. Rest of the biostatistical tools was used as per the requirement. $P<0.05$ were considered significant results.

\section{Anaesthesia technique}

All patients were kept fasting 6-8 hours for solid food and 3-4 hours for liquid before surgery. Patients were pre-medicated with oral diazepam $5 \mathrm{mg}$ night before and on morning of surgery. In addition all patients received injection morphine $0.1 \mathrm{mg} / \mathrm{kg}$ and promethazine 0.5 $\mathrm{mg} / \mathrm{kg}$ intramuscularly, 45 minutes before shifting to operation room. Anaesthesia technique was standardised for all patients. Induction of anaesthesia consisted of fentanyl $2 \mu \mathrm{g} / \mathrm{kg}$, thiopentone sodium $4 \mathrm{mg} / \mathrm{kg}$ and rocuronium $0.9 \mathrm{mg} / \mathrm{kg}$. Maintenance of anaesthesia included intermittent doses of midazolam, fentanyl, pancuronium and oxygen in air and isoflurane. Monitoring included continuous 5 lead ECG, invasive arterial blood pressure, central venous pressure, pulmonary capillary wedge pressure (PCWP), transoesophageal echocardiography, end tidal carbon dioxide, pulse oximetry $\left(\mathrm{SpO}_{2}\right)$, near infrared spectrometry (NIRS), core temperature, hourly urine output, intermittent arterial blood gases, electrolytes and blood glucose. Haemodynamic parameters and cerebral oximetry were maintained within normal range in both the groups. Any patient from either of the two groups, showing persistence hypotension (systolic $\mathrm{BP}<90 \mathrm{mmHg}$ ), dysrhythmias (ventricular tachycardia, fibrillation and fast rate atrial fibrillation) and low oxygen saturation $\left(\mathrm{PaO}_{2}<50 \mathrm{mmHg}\right.$ and $\left.\mathrm{SpO}_{2}<90 \%\right)$ in -CPB period were decided to be excluded from the study.

\section{Surgical technique and cardiopulmonary bypass}

Median sternotomy and pericardiotomy was performed to expose the heart. Saphenous vein and left internal 


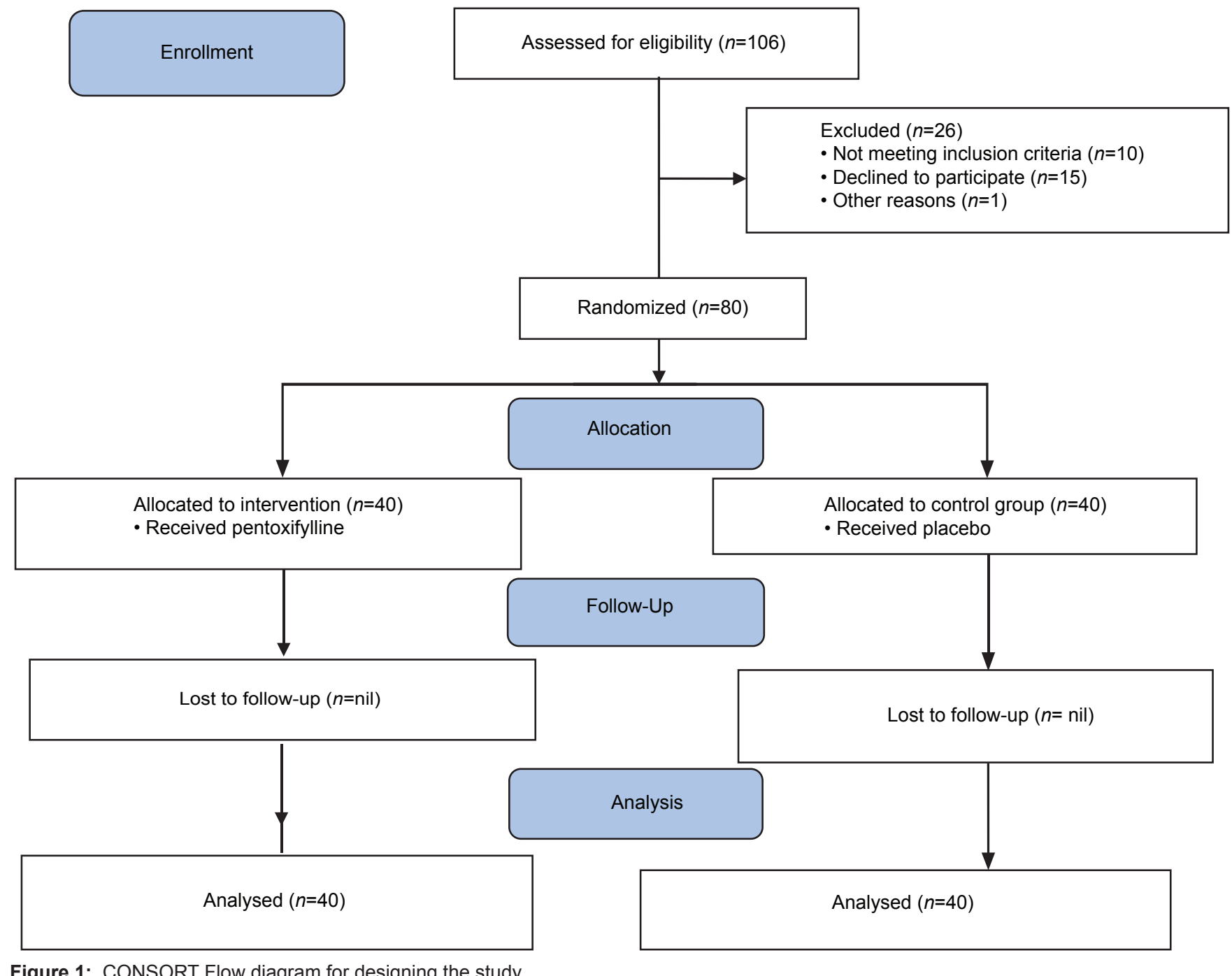

Figure 1: CONSORT Flow diagram for designing the study

mammary artery grafts were harvested. Systemic heparinisation was achieved with $400 \mathrm{IU} / \mathrm{kg}$ dose of heparin and ACT $>480$ seconds. Cardiopulmonary bypass was established with ascending aorta and two stage right atrial venous cannulation. The bypass circuit, hard-shell reservoir and membrane oxygenator were primed with 1.5 liters of ringer's solution, $0.5 \mathrm{mg} / \mathrm{kg}$ of mannitol and $5000 \mathrm{IU}$ of heparin, non-pulsatile flow of 2.2 to $2.4 \mathrm{~L} / \mathrm{min} /$ $\mathrm{m} 2$ with hypothermia up to $32^{\circ} \mathrm{C}$. The mean perfusion pressure was maintained between 60 and $80 \mathrm{mmHg}$ on pump. Cardiac asystole was achieved with multiple dose cold St. Thomas cardioplegia solution after application of aortic cross clamp. Haematocrit was maintained around $24 \%$ during $\mathrm{CPB}$. Patients were rewarmed to $36-37^{\circ} \mathrm{C}$ and heparin was neutralised with protamine sulfate in the ratio of $1: 1.5$. All operations were performed by the same surgical team. Duration of $\mathrm{CPB}$, number of vessels grafted, any perioperative use of blood, blood products, inotropes and use of IABP were noted. The decision for extubation and discharge from the intensive care unit was made according to the preset criteria.

\section{Neurocognitive assessment procedure}

All patients underwent neurocognitive testing with a battery of evaluations preoperatively at admission to hospital (baseline) and post operatively on 7th day. All evaluations were carried out by a trained and dedicated psychologist who was blinded to intervention and serological testing. The standardised battery induced three tests.

Post Graduate Institute memory scale (PGI-MS): The scale is part of the PGI battery of brain dysfunction developed by Pershad and Verma (1990). ${ }^{[10]}$ The battery is administered in Hindi, the first language of most patients, and has been developed and validated for use in the Hindi speaking population. It includes 10 subtests; of which all were used. These included remote and recent memory, forward and backward digit spans, delayed recall of a word list, immediate recall of sentences, visual recognition, visual retention, retention of similar word pairs and retention of dissimilar pairs. The procedure involved asking questions asked to patients as per 
subtest and the score assigned was the number of correct answers.

\section{Digit symbol tests}

The digit symbol substitution test (Wechsler, 1981) is a test of visuomotor coordination, motor persistence, sustained attention and response speed..$^{[11]}$ Rapid information processing is required in order to substitute the symbols accurately and quickly. The test consists of a sheet in which numbers 1-9 were randomly arranged in 4 rooms of 25 squares each. The subject substitutes each number with a symbol using a number-symbol key given on the top of the page.

\section{Procedure}

Test sheet is placed in front of the subject. The principle of substituting symbols for digits is explained. Practice is given for the first ten squares after which the test commences for a period of 90 seconds. The score assigned was the number of correct substitution.

\section{Animal naming test}

It consists of recalling maximum number of names of animals within one minute. The test assesses the fluency power and early cognitive impairment. Instructions followed are those of Rosen (1980). ${ }^{[12]}$

\section{Procedure}

The subject is asked to generate the names of as many animals as possible in one minute. The subject is asked to exclude the names of fish, birds and snakes. The score assigned was the total number of names generated.

\section{Postoperative neurocognitive decline}

Patients were considered to have POCD if they showed a deterioration of 1 standard deviation (SD) or more in two or more tests in the postoperative score compared to preoperative score. ${ }^{[3]}$

\section{Other parameters}

Any major cardiovascular, pulmonary, renal and neurological complications were recorded and those patients were excluded. Patients with re-exploration for bleeding were also excluded from the study. Time of discharge from ICU and hospital were recorded. Any serious adverse effects because of pentoxifylline administration was also noted and recorded.

\section{RESULTS}

A total of 80 patients were enrolled for the study, 40 patients in PTX group and 40 patients in placebo group [Figure 1]. All 80 patients cooperated to complete the study. The mean age of the control group $(58.1 \pm 6.7)$ was slightly higher than the study group $(56.4 \pm 7.7)$ and there were fewer patients in the from the urban area in the study group $(73 \%)$ as compared to control $(84 \%)$; however, the

difference was not statistically significant. There were a greater proportion of males in both the groups, as can be seen in [Table 1]. In the PTX group the minimum education was class IX. The difference between the two groups in terms of education was marginal $(P=0.05)$. Most patients belonged to the middle socio-economic status and were married as shown in [Table 1]. Both the groups were found to be comparable in terms of number of diabetics, $\mathrm{CPB}$ time, number of grafts used during $\mathrm{CABG}$, number of packed red blood cells used during and after $\mathrm{CPB}$, hospital discharge time, IABP support and requirement of high inotropes [Table 2]. The extubation time $(7.25 \pm$ $1.12 \mathrm{~h}$ vs $8.5 \pm 1.68 \mathrm{~h}, P=0.001)$ and ICU stay $(28.2 \pm 4.9 \mathrm{~h}$ vs $32.4 \pm 7.0 \mathrm{~h}, P=0.01$ ) were increased in placebo treated group. The nausea, vomiting and abdominal distension was similar ( $15 \%$ vs $12.5 \%, P=0.55)$ [Table 2 ].

\section{Cognitive function}

Results are reported according to the test used.

Animal naming test (ANT)-The animal naming test noted no statistically significant difference in pre and post-operative period in the PTX-treated group $(P<0.07)$. However, patients of placebo group showed significant difference in ANT, $(P<0.008)$ [Table 3].

Table 1: Demographic data

\begin{tabular}{|c|c|c|c|}
\hline Variables & $\begin{array}{c}\text { Group } \\
\text { PTX } \\
(n=40)\end{array}$ & $\begin{array}{c}\text { Group } \\
\text { Placebo } \\
(n=40)\end{array}$ & $P$ \\
\hline Age, mean (SD) & $56.4 \pm 7.7$ & $58.1 \pm 6.7$ & 0.36 \\
\hline Weight, mean (SD) & $69.6 \pm 10.3$ & $64.6 \pm 8.1$ & $0.04^{*}$ \\
\hline \multicolumn{4}{|l|}{ Marital status } \\
\hline Married & $39(96.7)$ & $40(100)$ & 0.46 \\
\hline Single & $1(3.3)$ & $0(0)$ & \\
\hline Male & $36(86.7)$ & $37(90)$ & 0.54 \\
\hline Female & $4(13.3)$ & $3(10)$ & \\
\hline \multicolumn{4}{|l|}{ Education } \\
\hline $5^{\text {th }}$ and below & $5(12.5)$ & $7(17.5)$ & 0.15 \\
\hline $6^{\text {th }}-8^{\text {th }}$ & $6(15)$ & $5(12.5)$ & \\
\hline $9^{\text {th }}-12^{\text {th }}$ & $14(35)$ & $12(30)$ & \\
\hline Graduate & $13(32.5)$ & $11(27.5)$ & \\
\hline Professional & $2(5)$ & $5(12.5)$ & \\
\hline \multicolumn{4}{|l|}{ Socioeconomic status } \\
\hline Lower middle & $5(12.5)$ & $5(12.5)$ & 0.21 \\
\hline Middle & $28(70)$ & $30(75)$ & \\
\hline Upper middle & $7(17.5)$ & $5(12.5)$ & \\
\hline \multicolumn{4}{|l|}{ Domicile } \\
\hline Urban & $30(75)$ & $28(70)$ & 0.26 \\
\hline Rural & $10(25)$ & $12(30)$ & \\
\hline
\end{tabular}


The digit symbol substitution test detected statistically significant difference in pre and post-operative period in placebo group [Table 3]. However, the decline in the values was less and cognitive functions were more preserved in intervention or PTX-treated group.

PGIMS- The preoperative base line 10 subtests of PGIMS of both groups showed no statistical significance on comparison [Table 4]. In the placebo group a significant difference was noted pre and post-operatively with increase in memory deficits in remote memory $(P<$ $0.01)$, recent memory $(P<0.04)$, mental balance $(P<$ $0.002)$, attention and concentration $(P<0.005)$ and visual retention $(P<0.02)$ [Table 5]. In contrast POCD was less in PTX-treated patients. Only two subtests were noted to have significant decline in the study group [Table 5].

The deterioration in cognitive score from admission to 7 thpostoperative day was detected in nine $(22.5 \%)$ patients in the PTX group and $20(50 \%)$ patients in the placebo group when $1 \mathrm{SD}$ or more was defined as POCD.

Table 2: Perioperative variables

\begin{tabular}{lccc}
\hline Parameters & $\begin{array}{c}\text { Group } \\
\text { PTX }\end{array}$ & $\begin{array}{c}\text { Group } \\
\text { Placebo }\end{array}$ & $P$ \\
\hline Diabetes mellitus & $12(30)$ & $14(35)$ & 0.51 \\
CPB time & $48.6 \pm 11.1$ & $47.38 \pm 14.5$ & 0.66 \\
Number of grafts & $3.2 \pm 0.6$ & $3.18 \pm 0.6$ & 0.6 \\
Number of PRBC used & $2.3 \pm 0.9$ & $2.2 \pm 0.7$ & 0.5 \\
during and after CPB & & & \\
Extubation time (hrs.) & $7.25 \pm 1.12$ & $8.5 \pm 1.68$ & 0.001 \\
ICU discharge (hours) & $28.2 \pm 4.9$ & $32.4 \pm 7.0$ & 0.01 \\
Hospital discharge (days) & $7.9 \pm 0.7$ & $8.0 \pm 0.8$ & 0.82 \\
IABP and high inotropes & $7(17.5)$ & $7(17.5)$ & 1 \\
$\begin{array}{l}\text { Nausea, vomiting and } \\
\text { abdominal distension }\end{array}$ & $6(15)$ & $5(12.5)$ & 0.55 \\
\hline
\end{tabular}

Continuous variables are presented as mean $\pm \mathrm{SD}$; discrete variables are presented as number (\%). Abbreviations: CPB: Cardiopulmonary bypass, ICU: Intensive care unit, IABP: Intra-aortic balloon pump, PTX: Pentoxifylline

Table 3: Pre and post-operative comparison of both groups on animal naming test and digit symbol substitution test (mean \pm SD)

\begin{tabular}{lccccc}
\hline Time & \multicolumn{4}{c}{ Mean \pm SD } \\
\cline { 2 - 3 } point & \multicolumn{2}{c}{ Group PTX } & & Group Placebo \\
\cline { 2 - 3 } \cline { 5 - 6 } & ANT & DST & & ANT & DST \\
\hline Pre-op & $10.3 \pm 2.2$ & $(26.1 \pm 7.47)$ & & $10.5 \pm 3.7$ & $(22.3 \pm 7.7)$ \\
Post-op & $9.4 \pm 2.5$ & $(22.2 \pm 6.07)$ & & $8.6 \pm 3.9$ & $18.4 \pm 8.9$ \\
$P$ & 0.07 & 0.09 & & 0.008 & 0.004 \\
\hline
\end{tabular}

Abbreviations: ANT: Animal naming test, DST: Digit symbol tests,

SD: Standard deviation, PTX: Pentoxifylline

\section{DISCUSSION}

The present study was carried out to estimate the effect of PTX on neurocognitive dysfunction in patients undergoing CABG. All the 3 NCA tests detected a significant reduction of POCD in intervention or PTX group in comparison to placebo-treated group. The incidence of POCD is $22.5 \%$ in PTX group and $50 \%$ in placebo group on the 7 th day postoperative period. The findings of our study replicate numerous welldocumented studies that have demonstrated the presence of neurocognitive deficits after CABG ${ }^{[3,4]}$ Decline in categorical verbal fluency by animal naming test was noted in the placebo group. The digit substitution test proved marked decline in motor persistence and response speed after surgery in placebo group. Poor performance by patients on remote memory, recent memory, mental balance, attention and concentration and visual retention functions was observed by PGIMS in the placebo group. However, in the PTX-treated group, the pre and post-operative difference was not significant on animal naming test, digit symbol substitution test and eight subtests of memory functions by PGIMS. The extubation time and ICU discharge time was higher in placebo group. This might be explained by reduction in pulmonary and tissue inflammation by PTX as proved by the study of Hering lake et al and Heinze et al..$^{[13,14]}$ But the hospital discharge time from hospital was similar and not statistically significant.

Cognitive function is the intellectual, memory and skillful activities of a person generated from the activities of brain. Cognition is a set of abilities, skills or processes that are part of nearly every human action. They have more to do with the mechanisms of how we learn, remember, problem-solve, and pay attention rather than with any actual knowledge. Post-operative cognitive decline after CABG will create problem in daily life activities. ${ }^{[2]}$ The person's abilities to react or solving the problems will be slower and hence the quality of life will be poor than prior to CABG. Hence, the hospital stay might be more and cost would increase. The person after CABG with higher POCD will resume the preoperative level of cognitive activity later. ${ }^{[2]}$

Brain injury from cardiac surgery has a range of manifestations, including stroke, encephalopathy, and/or neurocognitive dysfunction. ${ }^{[1]}$ A major area where the field has not made great progress in improving patient outcomes is brain injury following CPB. While stroke (type 1 deficit) is the most serious and carries an incidence of $1.5 \%$ to $5.2 \%$, neurocognitive dysfunction (type 2 neurologic deficit) is arguably the most common complication following cardiac surgery, with a shortterm incidence of $33-83 \%$ as well as a long-term incidence of $20-60 \% .{ }^{[15,16]}$ The present study detected the incidence 
of POCD of $50 \%$ on 7 th postoperative period in placebo group.

Pentoxifylline is xanthine derivative. ${ }^{[7]}$ Pentoxifylline is almost completely absorbed after oral administration. The $400 \mathrm{mg}$ PTX sustained release tablet showed an initial peak plasma concentration after 2 to $3 \mathrm{~h}$. The active main metabolite 1-(5- hydroxyhexyl)-3,7-dimethylxanthine is measurable in twice the concentration of its parent substance. ${ }^{[7]}$ Biotransformation products are almost exclusively eliminated by the kidneys. It belongs to a group of vasoactive drugs which improve peripheral blood flow and thus enhance peripheral tissue oxygenation. The mechanism by which PTX achieves this effect has not been determined, but it is likely due to improvement of red blood cell flexibility, vasodilatation and platelet disaggregation.

\begin{tabular}{lccc}
$\begin{array}{l}\text { Table 4: Comparison of preoperative PGI } \\
\text { memory scores }\end{array}$ & \multicolumn{3}{l}{} \\
\hline PGI memory subtests & $\begin{array}{c}\text { Group } \\
\text { PTX }\end{array}$ & $\begin{array}{c}\text { Group } \\
\text { Placebo }\end{array}$ & $P$ \\
\hline Remote memory & $5.69 \pm 0.549$ & $5.5 \pm 0.86$ & 0.426 \\
Recent memory & $4.96 \pm 0.196$ & $4.9 \pm 0.24$ & 0.664 \\
Mental balance & $7.23 \pm 1.751$ & $6.6 \pm 02.15$ & 0.352 \\
Attention and concentration & $8.31 \pm 1.087$ & $8.2 \pm 1.57$ & 0.616 \\
Delayed recall & $8.50 \pm 1.175$ & $8.16 \pm 1.26$ & 0.382 \\
Immediate recall & $9.69 \pm 1.738$ & $9.4 \pm 1.63$ & 0.471 \\
Verbal retention (similar) & $4.27 \pm 0.778$ & $3.9 \pm 1.14$ & 0.286 \\
Verbal retention (dissimilar) & $8.04 \pm 3.376$ & $7.6 \pm 3.89$ & 0.658 \\
Visual retention & $8.54 \pm 1.964$ & $8.1 \pm 2.19$ & 0.352 \\
Recognition & $6.61 \pm 1.888$ & $6.8 \pm 1.82$ & 0.398 \\
\hline
\end{tabular}

PGI: Post graduate institute, PTX: Pentoxifylline
The preservation of cognitive function in PTX-treated group could be because of the rheological benefits of PTX. ${ }^{[7]}$ PTX improves blood flow through cerebral blood vessels of the brain and improves red blood cell deformability, reduces blood viscosity and decreases the potential for platelet aggregation and thrombus formation in the moment of hypothermic non-pulsatile flow during $\mathrm{CPB}{ }^{[8,9]}$ The better cognitive function in the PTX group might be also because of reduction of inflammation; as proved by Cagli et al and Heringlake et al..$^{[6,14]}$ The adverse effects of PTX treatment are nausea, vomiting, abdominal distension and hypotension and tachycardia induced by vasodilation. ${ }^{[7]}$ But we did not observe any major haemodynamic and gastro-intestinal events with 400 mg twice daily dose of PTX comparing the two groups.

\section{Study Limitations}

The present study had not included elderly patients of age more than 65 year. Patients were only coronary artery disease with less co-existing diseases. The inflammatory markers like tumour necrosis factor (TNF) or interleukins were not measured to observe the anti-inflammatory property of PTX. The patients were small in number; a larger population will strengthen the finding. The neurocognitive functions were assessed only by three batteries of tests, which might not have examined all the neurocognitive functions. More number and different category of neurocognitive tests is required to give better verdict on the effect of PTX to reduce POCD.

In conclusion the present study suggests that pentoxifylline is useful in attenuating the early postoperative neurocognitive decline in patients undergoing coronary artery bypass grafting surgery using cardiopulmonary bypass.

Table 5: Pre and post-operative scores comparison of both groups (frequency) on subtest of PGI-MS (mean \pm SD)

\begin{tabular}{|c|c|c|c|c|c|c|}
\hline \multirow[t]{2}{*}{ Subtest } & \multicolumn{2}{|c|}{ Group PTX } & \multirow[t]{2}{*}{$P$} & \multicolumn{2}{|c|}{ Group Placebo } & \multirow[t]{2}{*}{$P$} \\
\hline & Pre & Post & & Pre & Post & \\
\hline Remote memory & $5.7 \pm 0.55$ & $5.3 \pm 0.74$ & $0.03^{*}$ & $5.5 \pm 0.86$ & $4.2 \pm 1.1$ & $0.001^{*}$ \\
\hline Recent memory & $4.9 \pm 0.19$ & $4.7 \pm 0.62$ & 0.05 & $4.9 \pm 0.24$ & $3.8 \pm 0.40$ & $0.004^{*}$ \\
\hline Mental balance & $7.2 \pm 1.75$ & $6.9 \pm 01.61$ & 0.43 & $6.6 \pm 02.15$ & $5.9 \pm 02.22$ & $0.003^{*}$ \\
\hline Attention and concentration & $8.3 \pm 1.08$ & $7.8 \pm 1.27$ & $0.019^{*}$ & $8.2 \pm 1.57$ & $7.5 \pm 1.50$ & $0.005^{*}$ \\
\hline Delayed recall & $8.5 \pm 1.17$ & $8.7 \pm 1.19$ & 0.30 & $8.16 \pm 1.26$ & $7.8 \pm 1.46$ & 0.17 \\
\hline Immediate recall & $9.7 \pm 1.74$ & $9.0 \pm 2.19$ & 0.10 & $9.4 \pm 1.63$ & $9.1 \pm 2.04$ & 0.35 \\
\hline Verbal retention (similar) & $4.3 \pm 0.77$ & $4.1 \pm 1.07$ & 0.50 & $3.9 \pm 1.14$ & $3.6 \pm 1.18$ & 0.09 \\
\hline $\begin{array}{l}\text { Verbal retention (dissimi- } \\
\text { lar) }\end{array}$ & $8.04 \pm 3.38$ & $7.1 \pm 3.84$ & 0.05 & $7.6 \pm 3.89$ & $7.4 \pm 4.01$ & 0.68 \\
\hline Visual retention & $8.5 \pm 1.96$ & $8.5 \pm 2.61$ & 0.91 & $8.1 \pm 2.19$ & $7.4 \pm 2.51$ & $0.02 *$ \\
\hline Recognition & $6.6 \pm 1.88$ & $6.3 \pm 2.0$ & 0.42 & $6.8 \pm 1.82$ & $6.6 \pm 2.10$ & 0.62 \\
\hline
\end{tabular}

SD: Standard deviation, PTX: Pentoxifylline 


\section{REFERENCES}

1. Roach GW, Kanchuger M, Mangano CM, Newman M, Nussmeier $\mathrm{N}$, Wolman R, et al. Adverse cerebral outcomes after coronary bypass surgery. Multicenter Study of Perioperative ischemia Research Group and the Ischemia Research and Education Foundation Investigators. N Engl J Med 1996;335:1857-63.

2. Newman MF, Grocott HP, Mathew JP, White WD, Landolfo K, Reves JG, et al. Neurologic Outcome Research Group and the Cardiothoracic Anesthesia Research Endeavors (CARE) Investigators of the Duke Heart Center. Report of the substudy assessing the impact of neurocognitive function on quality of life 5 years after cardiac surgery. Stroke 2001;32:2874-81.

3. Zamvar V, Williams D, Hall J, Payne N, Cann C, Young K, et al. Assessment of neurocognitive impairment after off- pump and on-pump techniques for coronary artery bypass graft surgery: Prospective randomised controlled trial. BMJ 2002;325:1268.

4. Newman MF, Kirchner JL, Phillips-Bute B, Gaver V, Grocott H, Jones RH, et al. Neurological Outcome Research Group and the Cardiothoracic Anesthesiology Research Endeavors Investigators. Longitudinal assessment of neurocognitive function after coronary-artery bypass surgery. $\mathrm{N}$ Engl J Med 2001;344:395-402.

5. Orhan G, Sargin M, Senay S, Yuksel M, Kurc E, Tasdemir M, et al. Systemic and myocardial inflammation in traditional and off-pump cardiac surgery. Tex Heart Inst J 2007;34:160-5.

6. Cagli K, Ulas MM, Ozisik K, Kale A, Bakuy V, Emir M, et al. The intraoperative effect of pentoxifylline on the inflammatory process and leukocytes in cardiac surgery patients undergoing cardiopulmonary bypass. Perfusion 2005;20:45-51.

7. Drug information on pentoxifylline (Trental) version 2007; Sanofi-Aventis Pharmaceutical, USA. Available from: http:// dailymed.nlm.nih.gov/dailymed/archives/fdaDrugInfo. $\mathrm{cfm}$ ?archiveid $=65977$. [Last accessed on $2010 \mathrm{Apr}$ ].

8. Banfi C, Sironi L, De Simoni G, Gelosa P, Barcella S, Perego C, et al. Pentoxifylline prevents spontaneous brain ischemia in stroke-prone rats. J Pharmacol Exp Ther 2004;310:890-5.

9. Eun BL, Liu XH, Barks JD. Pentoxifylline attenuates hypoxicischemic brain injury in immature Rats. Pediatr Res 2000;47:73-8.

10. Pershad D, Verma SK. Handbook of PGI battery of brain dysfunction (PGI-BBD). Agra, India: National Psychological Corporation; 1990.

11. Lezak MD. Neuropsychological assessment. Oxford: Oxford University Press; 1995.

12. Rosen, Rosen WG. Verbal fluency in aging and dementia. J Clin Neuropsychol 1980;2:135-46.

13. Heringlake M, Heinrichs G, Weber CF, Rosemann C, Bahlmann L, Eichler W, et al. The anti-inflammatory and organ-protective effects of pentoxifylline during cardiac surgery. Appl Cardiopulm Pathophysiol 2007;11:17-23.

14. Heinze H, Rosemann C, Weber C, Heinrichs G, Bahlmann L, Misfeld $\mathrm{M}$, et al. A single prophylactic dose of pentoxifylline reduces high dependency unit time in cardiac surgery - A prospective randomized and controlled study. Eur J Cardiothorac Surg 2007;32:83-9.

15. Gao L, Taha R, Gauvin D, Othmen LB, Wang Y, Blaise G. Postoperative cognitive dysfunction after cardiac surgery. Chest 2005; 128:3664-70.

16. Royter V, M Bornstein N, Russell D. Coronary artery bypass grafting $(\mathrm{CABG})$ and cognitive decline: A review. J Neurol Sci 2005;229-230:65-7.

How to cite this article: Das S, Kailash S, Mehta M, Bisoi AK. Perioperative pentoxifylline therapy attenuates early postoperative neuro-cognitive decline in patients undergoing coronary artery bypass grafting surgery using cardiopulmonary bypass. J Neuroanaesthesiol Crit Care 2015;2:44-50.

Source of Support: This study was conducted as a part of intra mural research fund from AlIMS, New Delhi, Conflict of Interest: None declared.

\section{Author Help: Reference checking facility}

The manuscript system (www.journalonweb.com) allows the authors to check and verify the accuracy and style of references. The tool checks the references with PubMed as per a predefined style. Authors are encouraged to use this facility, before submitting articles to the journal.

- The style as well as bibliographic elements should be $100 \%$ accurate, to help get the references verified from the system. Even a single spelling error or addition of issue number/month of publication will lead to an error when verifying the reference.

- Example of a correct style Sheahan P, O'leary G, Lee G, Fitzgibbon J. Cystic cervical metastases: Incidence and diagnosis using fine needle aspiration biopsy. Otolaryngol Head Neck Surg 2002;127:294-8.

- Only the references from journals indexed in PubMed will be checked.

- $\quad$ Enter each reference in new line, without a serial number.

- Add up to a maximum of 15 references at a time.

- If the reference is correct for its bibliographic elements and punctuations, it will be shown as CORRECT and a link to the correct article in PubMed will be given.

- If any of the bibliographic elements are missing, incorrect or extra (such as issue number), it will be shown as INCORRECT and link to possible articles in PubMed will be given. 